fatal year, of many Follies among the Wise, 1720." Here was described and pictured, in French, English, and Dutch by turns, John Law as Atlas supporting the world, as Don Quixote tilting at the wind-mills, as the "monopolist of wind." Several views of the Rue Quinquempoix were found (with a throng of Frenchmen even wilder than some curbstone real-estate exchange in the late Florida boom) dealing in the Mississippi Company's ventures. Two editions of the collection, differing in many details, were published in 1720. The Harvard College Library has one edition, and the Hallowell gift provides the Historical Society with the other.

\title{
A Railroad Item
}

A collection of early railroad history has been added to The Business Historical Society Collection. It covers the early history of the Delaware, Lackawanna, and Western Railroad Company. The fourth annual report contains a rare communication to the Evening Post of November 9, 1857, which brings up the history of the Cheever Controversy, in which some of the Wall Street Phelps family were interested.

The most interesting of the documents, however, is the History of the Recent Investigation into the Affairs of the D. L. \& W. R. R. Co., which "is designed to disabuse the minds of the stockholders, and, at the same time, to show the doubtful benefit, if not the positive evil, of such investigations and the unfairness of this one in particular." George D. Phelps of the Cheever Controversy episode seems to have been the storm centre. Mr. Phelps subjoins another document called "Confidential." There was a real fight on at this time, and in one instance the opposition apparently bribed some clerk to abstract from the files the confidential documents of the officers. Then follow other "confidential" items and another Review of the Report of the Investigating Committee.

In all there are nine separate documents, which cover the early history of this famous railroad thoroughly, with all the "dirty linen washed in public." Their value lies not only in possible analogies to present-day railroad history but in the methods of financing and the results of such financing. The result of this investigation was in many cases that perfectly innocent parties were injured, and it illustrated the principle of "The Forgotten Man" as expressed by the late William Graham Sumner. 